\title{
The Spark Orientation Effect for Improving Attention and Recall
}

\section{Emma Rodero'}

\begin{abstract}
Although some sound elements such as music or sound effects are commonly used in audiovisual messages, little research has been conducted to determine whether they guarantee better cognitive processing. The purpose of this study is to improve listeners' cognitive processing by determining the effectiveness of several sound elements in an audio message. We analyzed the capacity and the position in radio commercials of three orienting elements - appeals to the listener, music, and sound effects - to determine if and how they enhanced the listener's attention and recall. The findings indicated that the use of orienting elements significantly increased the level of attention and recall of the listeners, especially in the case of sound effects. Regarding the position of the orienting elements, the study showed they were used effectively when focused on the whole structure of the message, applying the so-called spark orientation effect.
\end{abstract}

\section{Keywords}

advertising, audio message, sound elements, attention, recall

\section{Introduction}

The audiovisual industry continues to seek ways to hold the listener's attention during commercial breaks (Miller \& Marks, 1992; Rodero, 2014). One of the most common strategies to produce audio messages in general, and advertising more specifically, is having elements such as music or sound effects accompany the voice to develop a more appealing message. This strategy seeks to create an acoustic contrast to the verbal information. Although these elements have been and are commonly used on radio,

\section{'Pompeu Fabra University, Barcelona, Spain}

\section{Corresponding Author:}

Emma Rodero, Department of Communication, Pompeu Fabra University, Roc Boronat, I38. 08018,

Barcelona, Spain.

Email: emma.rodero@upf.edu 
television, or the Internet, little research has been conducted to determine whether they guarantee better cognitive processing, in terms of attention and memory, among listeners. This is particularly important because in the case of an advertising message such as a commercial, optimal cognitive processing should be an expected consequence. If listeners do not pay attention to the message, they will retain few if any of the details in their memory. Accordingly, analyzing the cognitive processing of a listener exposed to this kind of message is a significant topic within the context of advertising communication.

Thus, a major question to be addressed is whether the mere use of these resources improves cognitive processing or if it is necessary to adopt a particular strategy. In this respect, the few studies conducted have produced mixed results, an indication that there is a need to adopt a strategy. In other words, the effective use of these elements does not simply depend on they being employed but rather on their nature and position within a message. First, it depends on their nature because speech, music, and sound effects have different sound qualities; speech is verbal information, music is a melody composition, and sound effects, if they are descriptive, are artificial sounds of reality (objects, animals). Therefore, as they are different by nature, they are supposed to function in a different manner. Second, their placement in a sound composition is important to underline the most important data of the message. This is why adopting a strategy to select which sound elements to include and where to place them in a message is necessary.

Accordingly, advertisers have a set of options at their disposal to make the audio message more effective. But what are the different effects of each option? How should they be used to improve the cognitive processing of the listener, in particular with the clear objective of improving recall? This experimental study analyzes the effectiveness of three sound elements - appeals to the listener, music, and sound effects - and how they should be applied to radio ads to enhance the attention and recall of the listener. It therefore addresses two questions: first, their effectiveness in a radio commercial to improve attention and recall and, second, if the position of these elements affects the cognitive processing of the listener. These are two issues that so far have not been addressed but may be answered by applying the spark orientation effect.

\section{The Spark Orientation Effect}

The spark orientation effect can be defined as a strategy for focusing the listener's attention on the important parts of a message by applying novel sounds. These sounds are called orienting elements (i.e., music or sound effects).

According to the theoretical framework for this study, the Limited Capacity Model of Motivated Mediated Message Processing (LC4MP), audio structural features such as music or sound effects can provoke an orienting response (Lang, 2000, 2006, 2009). As human beings have limited resources available to process a stimulus and as the goal in an advertising message is to grab the audience's attention, part of this message should be processed automatically. The automatic processes are those that individuals are not able to consciously control and do not demand an excessive amount of attention (Schneider, 
Dumais, \& Shiffrin, 1984). Audio structural features of the message, such as music or sound effects, can activate these automatic processes by provoking an orienting response (Potter, 2000, 2006; Potter, Lang, \& Bolls, 2008). This orienting response can be defined as a biologically hardwired response to new signals in the environment (Lynn, 1966). Therefore, it represents a temporary increase in a listener's attention to encoding novel or signal stimuli, which has been referred to as the "What is it?" response. For example, voice changes in radio advertising have been found to evoke orienting responses (Potter, 2000; Potter et al., 2008). When an orienting response occurs, automatic cognitive resources are allocated to process the novel signal. Therefore, according to the work by Potter (2000) and Potter et al. (2008), if the level of attention increases, it can be hypothesized that an orienting response to audio elements such as music or sound effects also should improve the recall of the information placed after them. Thus, owing to their distinctive nature and different acoustic/sound qualities, orienting elements should serve to "illuminate" those parts of the message to which the listener should pay attention in the same way several sparks would. This effect involves two principles - rupture of uniformity and targeting of information.

\section{Rupture of Uniformity}

When an element with different or novel features (an orienting element) such as a salient auditory stimuli (Olsen, 2002) or novel auditory stimuli (Potter, 2006) is placed in a sound context with uniform or constant properties, this deviating element will draw the listener's attention, causing an orienting response. This effect occurs due to hearing different acoustic qualities. Therefore, the first principle to be applied to a sound composition is a rupture in uniformity, which creates a contrast. An environment where sound is constant is likely to primarily arouse the subject's attention when the uniformity is broken with an element containing different properties. This contrast activates the attentive novelty detection, according to Tiitinen, May, Reinikainen, and Näätänen (1994). In this study, appeals to the listener through speech, music, and sound effects are the orienting elements used to break this sound uniformity.

The first orienting element is appeals to the listener. This grammatical figure, consisting of imperatives, vocatives, and interjections, draws the attention of the audience and therefore may improve memory, at least when combined with other textual strategies, as demonstrated by Rodero's (2014) study. This resource intends to increase listeners' attention through the use of nouns, verbs, or interjections that address listeners by referring to the things they do. For example, sensorial or perceptual imperatives (e.g., "look," "listen") can be used to focus the listener's attention on a particular part of the message. In addition, the vocatives most commonly used for this purpose in radio advertising are the names of the professions (e.g., "student!" "farmer!" ... ). If the listener receives the message as if it were intended for him specifically, the more likely it is that involvement, motivation, or identification with the content of the message will increase. In this manner, the persuasive action of the advertising message can be reinforced (Rodero, 2011). This strategy also performs an intensification function that focuses the listener's attention. The clearest examples of these strategies would be 
the interjections used to draw attention at any specific moment or to simulate an interaction at the beginning of the message. These resources with an appealing value also serve as mechanisms of emphasis (e.g., "eh!" "ah!”) that can be used to highlight important information (Hernández, 2006). They invite the listener to be prepared to receive a stimulus within a brief time. Accordingly, appeals to the listener can be used as a salient element in the spark orientation effect.

The second of the orienting elements is music. Several studies have shown the power of music in stimulating emotions and therefore in enhancing memory (Alpert, Alpert, \& Maltz, 2005; Bower, 1981; Chebat, Gelinas, \& Vaillant, 2001; Dubé, Chebat, \& Morin, 1995; Yalch \& Spangenberg, 1990). Music, with distinctive characteristics compared with the other orienting elements, should perform a leading role as it breaks the message's uniformity. However, its effect will depend on its typology and how it is implemented in the message (Brooker \& Wheatley, 1994). For this reason, many studies relating to the use of music in advertising have obtained different results. Music can both be distracting (Park, Mark, \& Young, 1986) and attract attention (MacInnis \& Park, 1991). If music remains in the background throughout the message, the principle of rupture of uniformity will not be fulfilled. Consequently, its ability to attract attention will be reduced, as shown by certain studies. Furthermore, the type of music inserted is a key factor. Salamé and Baddeley (1989) tested different types of music to measure recollection of nine-digit sequences visually presented. The findings suggested that vocal music caused significantly more disruption than adding silence or instrumental music. This seems logical, as the lyrics of vocal music may interfere with a verbal message. This effect has been studied using the oddball paradigm. This paradigm studies audiovisual stimuli interrupted by a deviant stimulus. If in a homogeneous auditory context, regularity is broken by presenting an unexpected deviating sound, the result is an involuntary orienting of attention toward this sound (Escera, Alho, Winkler, \& Naatanen, 1998). In this regard, studies by Boyle and Coltheart (1996) and Martin, Wogalter, and Forlano (1988) found a distorting effect on memory in the case of vocal music while there were no significant differences for instrumental music. Therefore, the effect is directly related to the nature of the orienting element (the type of music) that causes a different type of cognitive processing, as suggested by Kellaris, Cox, and Cox (1993). According to Berti and Schröger (2003), these results can be attributed to the highest priority in the processing of changes in the background on comparing them with other elements of the message. This means that when the background comes into competition for limited processing at a given moment, music changes are processed before the elements of the message (Fraser \& Bradford, 2013). If music acts as a distorting element (e.g., vocal music) or has too many changes that are inconsistent with the message content, the result will be impaired information processing and decreased memory. In these circumstances, however, if music stops and the distorting effect disappears, memory will increase. This is the effect that Olsen $(1995,2002)$ demonstrated. If a vocal message is played partly with strident music in the background and partly with silence, the part with silence will be remembered to a greater extent. This is explained by the disruptive effect caused by the nature of music. 
Because of those two effects, Fraser and Bradford (2013) recommended backgrounds with fewer harmonic changes and fewer instruments and with tempos at one of the extremes, slow or fast. Moreover, if the goal is to pay attention to the message, vocal music and familiar music should not be used (Rodero, 2005). Familiar music can distract from the content of the message because it evokes in the listener associations regarding the music. In other words, when listeners hear well-known music, memories about this song are evoked and then they cease to pay attention to the content. The music acts as a distraction.

The third orienting element analyzed in this study is sound effects. These elements play an important role in the spark orientation effect, as they are distinctive and with shorter duration than music. Despite their potential, they are elements uncommon in audiovisual messages, except in movies, and perhaps for that reason few studies of their functions have been conducted. One of the first studies on this phenomenon, which analyzed the impact of sound effects on dramatic speech, found no significant effect when they were used to enhance attitudinal acceptance of the message (Vincenzo $\&$ Hendrick, 1974). However, most subsequent studies have shown positive effects in their application.

A study by Potter, Lynch, and Kraus (2015), which examined production effects and jingles, showed orienting responses following the onset of these audio features. Conversely, the orienting response diminished in the third repetition, showing a habituation effect. Along with this, the research by Rodero (2012) demonstrated that descriptive sound effects are able to generate vivid visual images in the listener's mind, enhancing processing, as is the case with the studies by Miller and Marks (1992), Bolls (2002), and Bolls and Muehling (2007). Bolls and Lang (2003) also provided additional support for these conclusions when compared with high- and low-imagery radio commercials. The complex messages involved multiple changes and used sound effects. The main conclusion was that listeners allocated more controlled cognitive resources to encoding the high-imagery commercials. Potter and Choi (2006) also analyzed the structural complexity in radio messages. The work of these authors established a relationship between these types of messages and their capacity to retain the listener's attention. Closer along the lines of our purposes are the studies by Potter (2006) and Potter et al. (2008). Potter (2006) concluded that a higher degree of memory was achieved when synthesized auditory effects (laser and echo) were used in the message, although the difference was not significant. Potter et al. (2008) showed that sound effects, as auditory structural features of radio messages, provoked an orienting response that increased the recognition memory for information after them. With the exception of these studies, the ability of sound effects to increase attention and memory is an aspect that has been less studied than music.

The rupture of uniformity can be attained to a greater or lesser extent with the mentioned orienting elements. However, there are other factors to provoke a rupture beyond simply placing orienting elements. If strident music is suddenly inserted in the middle of a speech, the listener's attention will be steered toward it, but this change will not necessarily result in greater recall of the message. When dealing with 
a media message, the problem is that the contrast always must be provoked according to the meaning of the content. Therefore, if the purpose is to enhance memory, matching the content of the message to the nature of the orienting elements is important. Kellaris et al. (1993) and MacInnis and Park (1991) confirmed that incongruent music paired with the message had a large distorting effect and hence a bearing on recognition and recall of information. If music does not add more to the context, it may compete with the text rather than facilitate recall (Wallace, 1994). Furthermore, Crowder, Seranne, and Repp (1990) showed that recognition was strengthened when melody established a connection with the text. Consequently, using pop music unrelated to the message will produce a different effect than music specifically adapted to it. The same effect similarly will not be produced when a synthesizer effect is used instead of a sound effect that is descriptive of a natural element related to the content. In this respect, studies by Jones (1993) demonstrated that the more segmented background music is, the more it interferes with memory in a recall series. Thus, the more incongruent the element with respect to the environment, the more it interferes with information recall.

As shown in this literature review, there are several studies devoted to analyzing the appeals to the listener, music, and sound effects functions as orienting or deviant elements, but there is no research about which one can achieve a strongest level of attention and recall depending on their or acoustic features. Therefore, we do not know if their cognitive processing is different.

Sound effects can be considered as the more salient stimuli in this study, as these sound features are not very common in radio commercials. Listeners are especially used to hearing voices and music, but sound effects are less frequent on radio. Therefore, the greater level of novelty provided by sound effects should increase the level of attention. Sound effects should be followed by music as the second stimulus acoustically different from verbal information.

Regarding recall, the same order can be predicted although for different reasons. As descriptive sound effects can be used providing meaning to the content of the message (i.e., the sound of a lion for an African getaway), those can reinforce the recall of information by direct association (the sound of a lion refers to a real object/animal). Similarly, if music is congruent with the content (i.e., Hawaiian music for a Hawaii getaway), it can attain the same effect, although in this case by indirect association (as there is not a reference to a physical object).

Therefore, our research questions here are as follows: Can these orienting elements improve the cognitive processing of the listeners exposed to audio commercials? And if so, which ones will achieve better levels of attention and recall? This leads us to formulate the first two hypotheses of this study:

Hypothesis 1: The commercials with orienting elements will attain higher levels of attention and recall than the commercials without them.

Hypothesis 2: The commercials with descriptive sound effects followed on the second position by ads with music will achieve better levels of attention and recall than the commercials with appeals to the listener. 


\section{Targeting of Information}

To strengthen attention and recall of the information, the most important parts of the message should be focused or "illuminated" to highlight them (Olsen, 2002). Therefore, respecting another principle - targeting of information - is very important. The orienting elements should fulfill the function of highlighting the important parts of the message to enhance understanding. This means that analyzing their position, frequency, and duration is relevant. Where and how often should the orienting elements be placed and for how long should they be played in the message to reinforce memory? There is no single answer to this question because it will depend on the characteristics of the message and especially on its structure. There are studies that establish a relationship between memory and organization of data in a message through a clear structure. Placement of the music is an influential factor to reinforce recall in a radio commercial (Brooker \& Wheatley, 1994). Therefore, concluding that these elements should reinforce several parts of the structure seems logical. For example, they may be effective especially in the introduction (the hook), in the middle (main information), and in the closing part of the message (conclusion and repetition of main data), as these are the three parts or segments to structure a commercial. Sharma (2011) and Brooker and Wheatley (1994) suggested that music used at the beginning of an advertisementmeaning it is not in the background-had positive effects on memory and improved brand attitude, according to studies by MacInnis and Park (1991).

In addition, the orienting elements must be located before the main part they are focusing on. This is how Potter (2006) introduced them in his research producing an orienting response and better recognition. Moreover, studies by Potter (2000), including voice changes in audio messages, and Thorson and Lang (1992), using cuts in a television messages, demonstrated that recognition of information increases 3 seconds after the orienting elements. Therefore, immediately after them there is an adapting time, where recognition accuracy has been shown to significantly decrease.

Regarding duration, it must be considered that if the orienting element is played in the message for an extended amount of time, the environment will become uniform again, the listener will get used to this new situation, and his attention will thus be lost. This means that an awareness of time affects the listener's perception of uniformity. According to this perspective, there are some studies that can provide guidance on the approximate duration of these elements. Some authors suggest that for speech the rate of memory decay stored in the phonological store is about 2 seconds (Baddeley, Eysenck, \& Anderson, 2015). Beyond these 2 seconds, the memory of the elements begins to decrease because the information cannot be emphasized to a great extent or the effect of focusing is lost. Therefore, the beginning and the end of the orienting element must be limited to briefly cause a distinctive effect. Then, between the orienting element and the main information to recall, there should be at least 3 seconds of adapting time - two corresponding to the decay of the orienting element and one more to orient the attention to the main information - in accordance with Potter's (2000) study. However, what remain unclear are the frequency and the placement of orienting elements in the message. Based on the literature, it can be predicted that the stimulus 
should occur often enough to highlight the main parts of the ad (introduction, development, and conclusion), that is, its structure, and should be placed before the main element they are focusing on. This leads us to formulate the third hypothesis:

Hypothesis 3: The commercials with the orienting elements placed on the three main parts of the message will achieve better levels of attention and recall than those only placed in one part of the message (introduction, or development, or conclusion).

To conclude, for the spark orientation effect to occur, the two main principles explained earlier must be fulfilled. In addition, the orienting element must have a nature consistent with the content of the message, be placed in strategic positions before the main information (product, price, characteristics, where you can buy it ...), and not be too long. This study has been designed precisely to analyze whether this effect really works to enhance the cognitive processing of listeners.

\section{Method}

\section{Design}

The design was a 3 (orienting element) $\times 4$ (position in message) between-subjects experiment. Participants listened to eight different commercials, no repeating content, but varying the version and the position. The order of presentation was randomly modified to eliminate order effects. The first factor, Orienting Element, had three elements - appeals to the listener, music, and sound effects. The second factor, Position in Message, was formed by four positions: at the beginning of the commercial (introduction), in the middle (development), at the end (conclusion), or in all three positions (at the beginning, in the middle, and at the end). There was also a control group in which participants listened to the eight real commercials selected from radio; therefore, they listened to the nonmanipulated version of those commercials.

\section{Stimuli}

One hundred fifty Spanish advertisements recorded from the most popular radio shows among young people were compiled because the target audience was comprised of university students. The first criterion was that the ads offered products or services of interest to university students to ensure listeners' involvement and motivation. To this end, a pretest was performed. Twenty students ( 10 women and 10 men) were randomly selected by alphabetical order and gender using class lists. They listened to the ads and rated them in order of interest through a Likert-type scale (from 1 to 5). The question was "To what extent are you interested in this product?" The most rated commercials with the largest significant differences in each category were selected for this study: technology (tablet), food (pizza), service (humanitarian tasks), education (university), learning of languages (English), sports (competition), aesthetics (hair removal center), and tourism (trip). The commercials had the typical characteristics of ads in Spain - information structure, a 
Table I. Corpus.

\begin{tabular}{|c|c|c|c|c|}
\hline Orienting elements & Number & Positions & Number & Total \\
\hline \multicolumn{5}{|l|}{ Version I } \\
\hline Ads selected from radio & 8 & No elements & I & 8 \\
\hline \multicolumn{5}{|l|}{ Version 2} \\
\hline $\begin{array}{l}\text { Ads selected from radio }(\mathrm{VI}) \text {, adding } \\
\text { appeals to the listener }\end{array}$ & 8 & $\begin{array}{l}\text { Beginning } \\
\text { Middle } \\
\text { End } \\
\text { The three positions }\end{array}$ & 4 & 32 \\
\hline \multicolumn{5}{|l|}{ Version 3} \\
\hline $\begin{array}{l}\text { Ads selected from radio }(\mathrm{VI}) \text {, adding } \\
\text { music }\end{array}$ & 8 & $\begin{array}{l}\text { Beginning } \\
\text { Middle } \\
\text { End } \\
\text { The three positions }\end{array}$ & 4 & 32 \\
\hline \multicolumn{5}{|l|}{ Version 4} \\
\hline \multirow[t]{2}{*}{$\begin{array}{l}\text { Ads selected from radio (VI), adding } \\
\text { sound effects }\end{array}$} & 8 & $\begin{array}{l}\text { Beginning } \\
\text { Middle } \\
\text { End } \\
\text { The three positions }\end{array}$ & 4 & 32 \\
\hline & Total & & & 104 \\
\hline
\end{tabular}

single voice, and being 30 seconds in duration, as described by some authors (Rodero, 2011). Finally, eight typical commercials for different brands were selected by this method.

Once the text of each advertisement was extracted, the commercials for Version 1 were recorded by a male voice-over as if they were the original ones, using the text and no added sound elements. Accordingly, the content of these ads was the same listened to on the radio. In Version 2, using the same ads, appeals to the listener were added. Then, music was added to the initial ads to prepare Version 3. Lastly, Version 4 was produced on the basis of the other three; however, in this instance, sound effects were applied. Table 1 shows the corpus.

The orienting elements included several characteristics. The music was instrumental, not familiar (music for audiovisual productions from libraries), and consistent with the content of the ad. The sound effects were of a descriptive nature, in other words, adding context to the scene (the sound of animals or objects, etc.) and also consistent with the content of the ad.

To analyze the position and frequency of the orienting elements in Versions 2, 3, and 4, they were placed in four different spots: (1) at the beginning of the ad (introduction), (2) in the middle (development), (3) at the end (conclusion), or (4) in all three positions (at the beginning, in the middle, and at the end; hence, the whole structure). The elements were placed before the important data of the message (product, price, characteristics, where you can buy it, etc.) and lasted at least 2 seconds. Between the onset of the orienting element and the main information were at least 3 seconds, so the listeners should have enough time to correctly encode the information after them (see Appendix). 


\section{Dependent Variables}

The attention variable was measured using a question regarding the degree of attention that the subjects had paid to the message- "How much attention have you paid throughout the commercial?" The answers were measured on a scale of 5 points with 1 representing the minimum value and 5 the maximum degree of attention. This scale was complemented with a final question about which commercial had reached their highest level of attention. Along with this, participants also completed an open-ended question about the reason for paying attention.

Furthermore, this experiment used the measuring of recall rate as a method to assess the cognitive subprocess of information storage in people's memory (Lang, 2009). The free recall questionnaire was comprised of five open-ended questions about key data in the ad - that is, content related to the main commercial message of the product (e.g., What was the product announced in this commercial? What was the price of the product?). The questionnaire did not have questions about the brand as they are the easiest elements to remember and the ads were about consolidated companies. In the blind evaluation, correct answers were those where participants provided precisely the information requested (e.g., What was the product announced in this commercial? A tablet. How much was the product announced in this commercial? 119 euros). As the example shows, the questions asked for concrete information about the products. Therefore, only those answering exactly the same, as mentioned in the commercial, were considered correct. The wrong answers were those where the participant did not correctly answer the requested information or did not answer the question at all (e.g., What was the product announced in this commercial? A phone).

\section{Participants}

Once the stimulus was created, a sample formed by Spanish university students $(n=$ 260 students, 138 women and 122 men, aged between 20 and 22 years) was randomly selected combining the lists of students enrolled in four different courses. These lists were then stratified into quartiles by last name (A-F, G-L, etc.). Sixtyfive students were randomly selected from each strata resulting in 260 participants.

\section{Procedure}

The participants were gathered in a room with optimal sound conditions. They were verbally informed that they would listen to several radio commercials and then would answer a questionnaire. This was the only direction; therefore, they were not informed about the measures that would be assessed (attention and recall). After the instructions, the advertising versions were reproduced. Every participant listened to eight different ads and answered the attention and recall questions by each commercial. One of these groups was the control group that only listened to the real commercials. The test lasted 30 minutes. 


\section{Analysis}

To test the levels of attention and recall of the real commercials and the ads with orienting elements, an 8 (advertisements) $\times 3$ (orienting elements) $\times 4$ (positions) MANOVA was conducted. To test the levels of attention and recall of the commercials with orienting elements, a 3 (orienting elements) $\times 4$ (positions) MANOVA was conducted.

\section{Results}

Using an alpha level of .001 to evaluate homogeneity assumptions (Tabachnick \& Fidell, 2012), Box's $M$ test of homogeneity of covariance was not significant ( $p=.028)$. Levene's homogeneity of variance test was statistically nonsignificant (attention: $p<.040$, recall: $p<.219$ ) making it possible for the assumption that the variations were in line with the principle of homoscedasticity. The dependent variables resulted in significant main effects for orienting elements and positions of these elements. The two-way interaction of orienting elements by positions as well as the order were not statistically significant. The test between subject effects revealed that, for the orienting elements, the difference was significant for attention, $F(7,253)=73.55, p<.001$, and recall, $F(7,253)=60.39, p<.001$. For the position, the difference was also significant for attention, $F(3,257)=35.02, p<$ .001 , and recall, $F(3,257)=29.86, p<.001$. Table 2 shows the statistics.

\section{Hypothesis I}

The first hypothesis of this study established that the commercials with orienting elements should attain higher levels of attention and recall than the commercials without them. This hypothesis is supported as the commercials that were unaffected by the application of an orienting element - the real ads-drew less attention and recall (attention: $M=2.89, S D=1.05$; recall: $M=2.20, S D=1.47$ ) than those in which an orienting element was introduced (attention: $M=3.86, S D=1.16$; recall: $M=3.24$, $S D=1.20)$. The differences were statistically significant for both attention, $F(1,359)$ $=60.69, p<.001$, and recall, $F(1,359)=31.80, p<.001$.

\section{Hypothesis 2}

The second hypothesis stated that the commercials with descriptive sound effects and music on the second position should achieve better levels of attention and recall than the commercials with appeals to the listener.

Regarding attention, the version with sound effects followed by the ads with music showed higher incidences of attention than the ads with appeals to the listener with a significant difference, $F(2,358)=15.26, p<.001$.

The answers in which participants were asked about the ad that achieved the most attention were measured by a Pearson's chi-square test. In this case, the commercials with sound effects also obtained the highest frequency (113), followed by music (105), and appeals to the listener (25), with a significant difference, $\chi^{2}=16.80, p<.001$. To the question about why they paid attention to these ads, the main reasons for textual 
Table 2. Attention and Recall of the Orienting Elements.

\begin{tabular}{lcc}
\hline Version & $M$ & $S D$ \\
\hline Attention & & \\
Real ads & 2.58 & 0.89 \\
Appeals & 3.18 & 0.86 \\
Music & 4.16 & 0.28 \\
Sound effects & 4.20 & 0.98 \\
Recall & & \\
Real ads & 1.14 & 1.23 \\
Appeals & 2.31 & 1.15 \\
Music & 2.78 & 1.19 \\
Sound effects & 3.77 & 1.21 \\
\hline
\end{tabular}

strategies were related to the text ("there are claims," "it is directed to me") or were related to the product ("I like the product," "I'm interested in the product,"; "it is for university students"). The most common reasons why students paid attention when the ads had music were simply because they had music. Finally, what caught the subjects' attention regarding ads with sound effects was the "emotion, simplicity, creativity, and rhythm." Figure 1 shows the mean values for the attention variable.

Regarding recall, the version with sound effects followed by the ads with music showed higher levels of recall than the commercials with appeals to the listener with significant differences, $F(2,358)=15.38, p<.001$. Figure 2 shows the mean values for the recall variable.

As a result, the rupture of uniformity provoking contrast by using different orienting elements attained a positive effect on the listener's attention and memory. The highest level was obtained by sound effects, followed by music and, lastly, appeals to the listener. Therefore, Hypothesis 2 also can be confirmed.

\section{Hypothesis 3}

The third hypothesis was related to position. This hypothesis suggested that the commercials with the orienting elements placed on three different parts of the message should achieve better levels of attention and recall than those only placed in one part of the message (introduction, or development, or conclusion). The commercials with the best levels of attention and recall were those that inserted the orienting elements in all three positions - at the beginning, in the middle, and at the end of the message. Therefore, this hypothesis also was verified. The results are in Table 3.

Messages with the orienting elements placed on three different parts of the message resulted in the highest self-reported attention with significant differences, $F(3,257)=$ $35.02, p<.001$. The orienting elements placed only at the beginning, only in the middle, or only at the end of the commercials obtained the second position, although with no significant differences among them, as shown in Figure 3.

Also, commercials with the orienting elements placed on the three parts of the message (beginning, middle, and end) obtained the highest level of recall with significant 


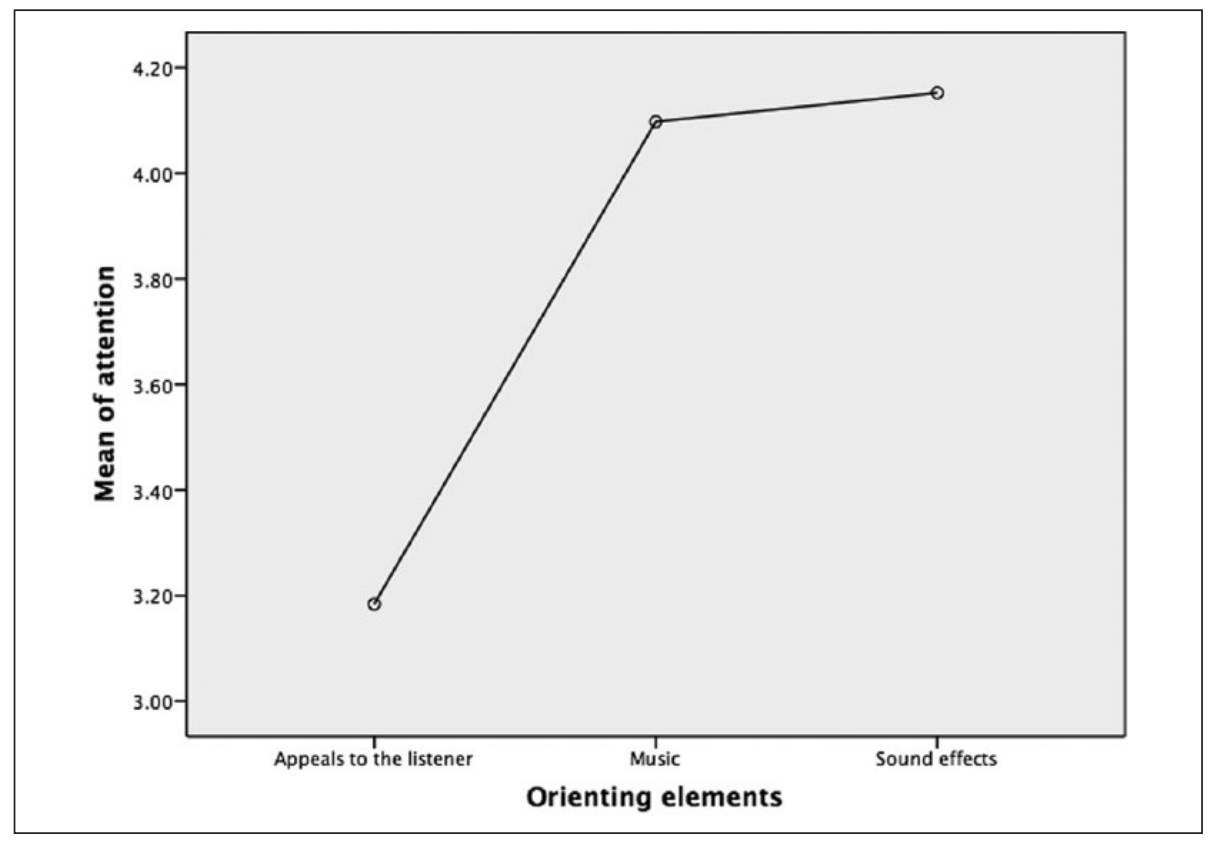

Figure I. Attention to the orienting elements.

differences, $F(3,257)=29.86, p<.001$. There were also significant differences between the orienting elements placed only at the beginning and those placed only in the middle and only at the end, as illustrated in Figure 4.

In conclusion, the commercials with the highest degree of attention and memory were indeed those "illuminating" the key data in each part of the message structure. Therefore, these findings confirm the spark orientation effect. The orienting elements acted from time to time refreshing the attention and enhancing the memory of the listener.

\section{Discussion}

The purpose of this study was to determine the effectiveness of the spark orientation effect in an audio message to improve listeners' cognitive processing in terms of attention and memory. The spark orientation effect is a strategy for focusing the listener's attention on the important parts of a message by applying novel sounds called orienting elements. To this end, we analyzed the effectiveness and the position of three orienting elements (appeals to the listener, music, and sound effects) to attract the listener's attention and to improve recall. The findings indicate that the application of the spark orientation effect obtained positive results. The use of orienting elements significantly increased the level of attention and recall of the listeners, especially in the case of sound effects. Regarding position, the most effective option was highlighting the whole message structure at the beginning, in the middle, and at the end of the commercial focusing on the most important information. 


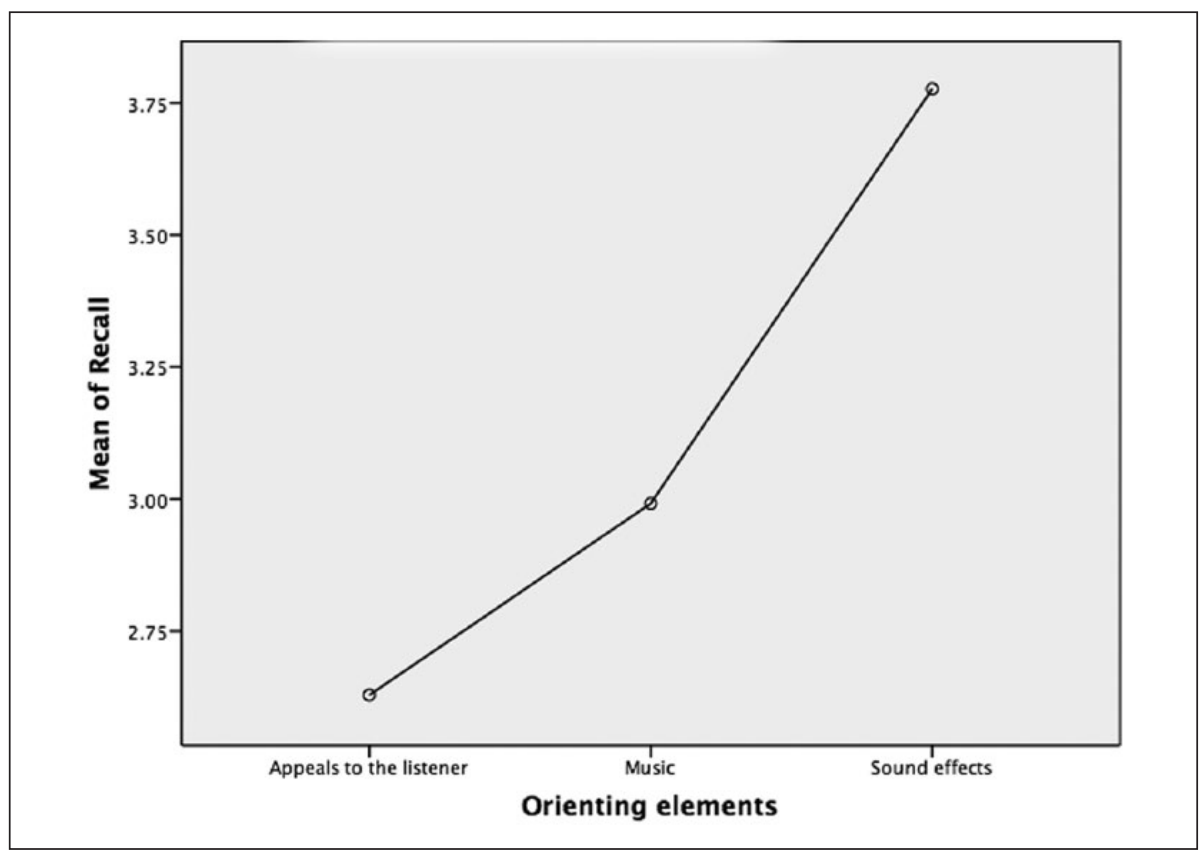

Figure 2. Recall of the orienting elements.

This study confirmed that the rupture of uniformity in an audio message contributes to increase the levels of attention and memory of the participants. To this end, the findings indicated that the more novel and distinguished the orienting element used, the more effective the result obtained in terms of message processing. As the sound effects were perceived as a novel signal, they could elicit an orienting response that increased the levels of attention. This result can be explained because the use of sound effects is uncommon in radio commercials. Thus, the highest degree of novelty in the stimulus, introduced by these sound effects in contrast to verbal information, made it possible to allocate more automatic resources to process the message. According to the LC4MP, as the available resources were high, the message was more thoroughly processed, and consequently the recall obtained the best levels. This idea can be reinforced with the feedback from the participants. They commented that the sound effects introduced "emotion" and "creativity." Consequently, they perceived these elements as creative and, in this sense, novel. This finding is consistent with the literature previously reviewed (Bolls \& Lang, 2003; Bolls \& Muehling, 2007; Miller \& Marks, 1992; Potter, 2006; Potter \& Choi, 2006; Potter et al., 2008; Potter et al., 2015; Rodero, 2012). Moreover, as the descriptive sound effects provided reference-based information ("what"), they also reinforced the content of the message. When the participants listened to sounds of a tablet in the commercial selling it, they associated this sound with its referent. Therefore, sound effects acted as contextualassociative elements strengthening the content of the message. Thanks to this association, participants then created an automatic mental image of the product, according to Rodero's 
Table 3. Attention and Recall by Position.

\begin{tabular}{lll}
\hline Position & $M$ & $S D$ \\
\hline Attention & & \\
Beginning & 3.62 & 1.13 \\
Middle & 3.61 & 1.14 \\
End & 3.59 & 1.26 \\
Three positions & 4.09 & 1.19 \\
Recall & & \\
Beginning & 3.47 & 1.38 \\
Middle & 2.62 & 1.24 \\
End & 2.58 & 1.25 \\
Three positions & 3.77 & 1.25 \\
\hline
\end{tabular}

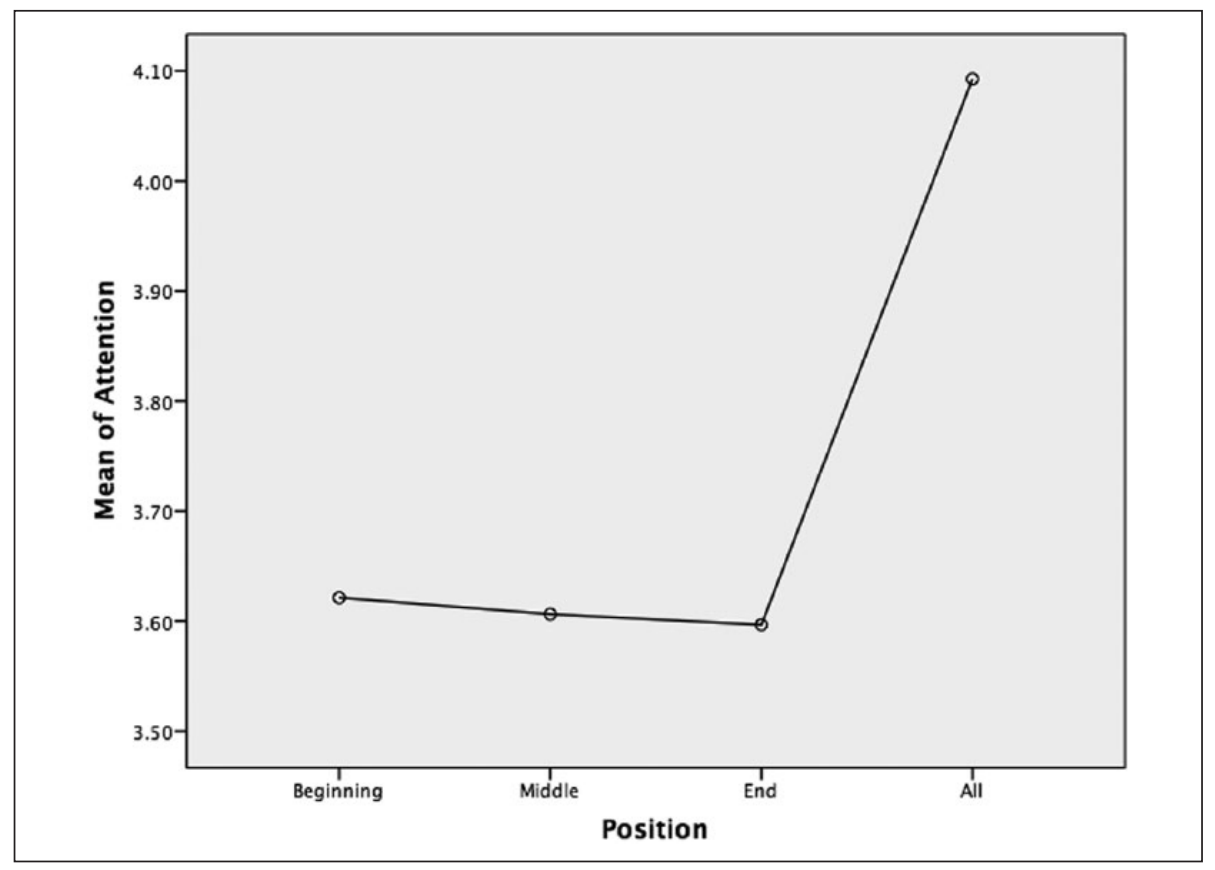

Figure 3. Attention by position.

(2012) study. The cognitive processing of the listener was visual and easier, as shown by the participants' responses when they mentioned "simplicity" and "rhythm." Due to the contextual function along with the automatic processing via mental images stimulation, the recall of information was finally improved. In conclusion, the sound effects made a contribution to the content of the message (more creativity, more rhythm, and more emotion), which may have strengthened it, enhancing recall. 


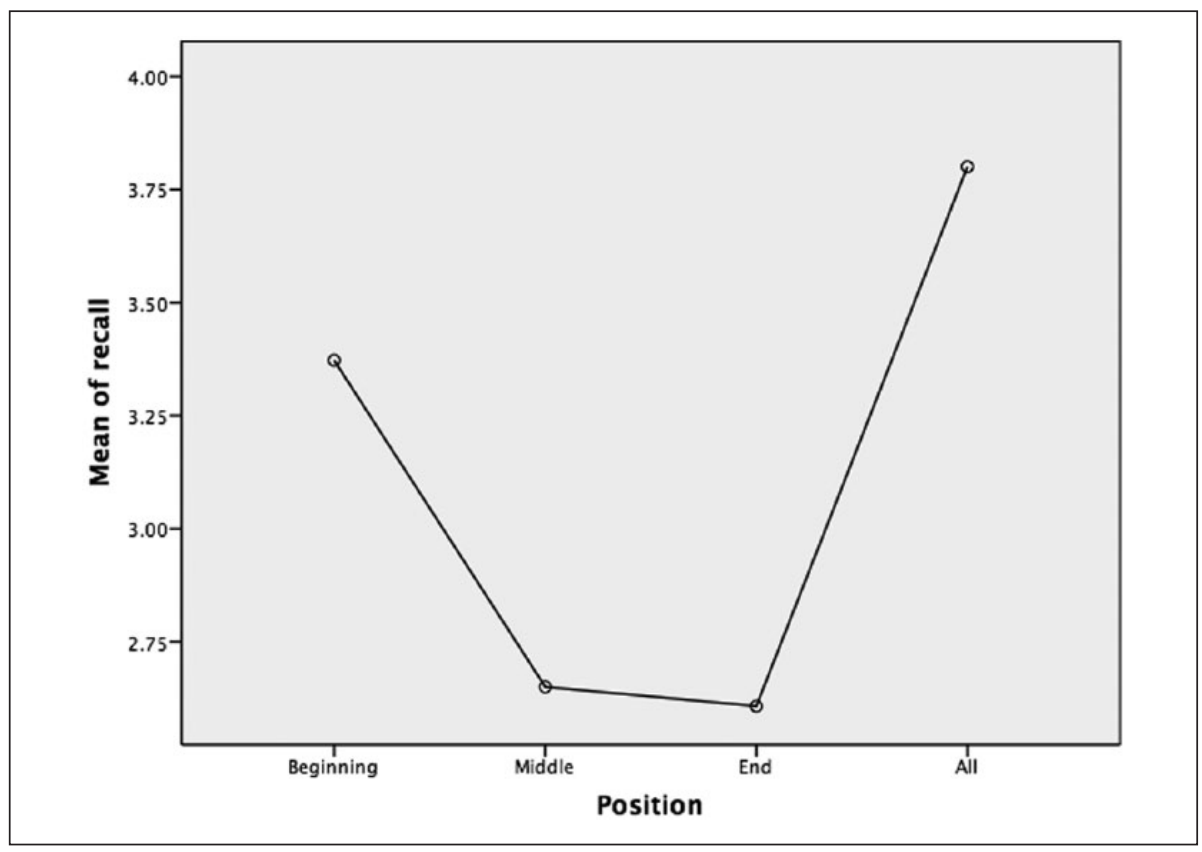

Figure 4. Recall by position.

Likewise, the ads with music achieved the second position, both for self-reported attention and recall, because music produces an important contrast in comparison with words. As music is also interpreted as a novel signal, it is able to elicit orienting responses. In this study, it can be suggested then that music could provoke an orienting response that increased the levels of attention. As a consequence, more resources were automatically allocated to encoding the message and the cognitive processing was easier. Furthermore, as music was congruent with the content in this study, the expected result was positive. When music is congruent with the content, this sound element can reinforce it by indirect association. Music can be associated with objects, ideas, or people. With music, there is not a real reference, as with sound effects, but as long as this association is recognizable, the encoding process can be easier because it is also automatic. This is what seems to have occurred in this study. However, an interesting aspect to analyze regarding music was the response of the participants when asked why they paid attention to the ads with music. The response was simply because these commercials had music. This means that music was less related to content than sound effects. It may be suggested that music acted in an emotional level, increasing the levels of attention and arousal. This is why participants could not explain the reasons why they paid attention. In conclusion, music was processed in a different manner than sound effects and therefore obtained lesser levels of attention and recall. Music was more recognizable for participants, which elicits less attention than sound effects. Furthermore, its 
relationship with the content was less direct, and then recall was lower. Finally, music oriented the attention of the participants via emotion. If participants liked the music, then the music caught their attention, but they did not know the reason.

Appeals to the listener were strategies that contributed to increasing the levels of attention and memory but to a lesser extent than sound effects and music. As they did not introduce a noticeable contrast and the rupture of uniformity was less evident, their effectiveness was lower than the other sound elements. Therefore, this speech strategy improved the levels of attention and recall but to a lesser extent due to its different kind of cognitive processing. The verbal condition of this resource could have triggered a mechanism more linked to semantic processing rather than visual (sound effects) or emotional (music) processing. The activation of semantic structures in the memory would not have benefited then from automatic processing. As no perceptual structures were activated in response to these commercials, participants had less available resources to process the message and, consequently, recall was hindered. Proof of this different cognitive processing lies in the fact that the subjects made comments relating to the content of the messages such as "I like the product," "I'm interested in it," and "It is for university students." The subjects referred to the content of the message because a clear distinguished sound element was missing.

In summary, the three orienting elements fulfilled the objective of improving the cognitive processing of listeners by increasing their levels of attention and memory, although this was achieved via different ways of processing, depending on their diverse features.

In analyzing the position of the orienting elements, the study showed they were used effectively when focused on the three different parts of the message (beginning, middle, and end). Thus, the most memorable ads were those underlining the important data in the three main parts of the commercials, according to the spark orientation effect. The orienting elements came in small flashes "illuminating" the whole structure of the message in which the listener had to pay more attention. The underlying idea of these findings is the need to insert short "sparks" of attention from time to time to indicate where paying more attention is necessary because the important information is there. This is a clear orientation strategy to maintain the listener's attention throughout the message and, consequently, to improve recall of information. However, when the orienting element only "illuminates" part of the message, the study did not achieve conclusive results in terms of attention. The stimulus seems to not have occurred often enough. This was the case for the initial, middle, and final positions of the orienting elements in the message. In contrast, regarding recall, the initial position obtained the second best results. This may be due to the fact that the orienting element located in this position acted as an introduction preparing the subjects to pay attention to the message, according to studies by Sharma (2011) and Brooker and Wheatley (1994). In addition, the element in the initial position was the only one in a situation of evident contrast because, before it, there was silence. For logical reasons, this did not happen with the middle and end positions. In any event, the strategy of emphasizing certain elements of the message with an orienting element, regardless of its position, obtained positive results when compared with commercials that did not employ any orienting element. All in all, with regard to the rupture of uniformity provoking contrast for targeting information, this study demonstrated the effectiveness of the spark orientation effect. 
While this effect is applied to audio messages, the results obtained in this study indicate that it might also be positive when applied in general to audiovisual messages and not merely advertising but also other fields such as entertainment or education.

\section{Limitations and Future Research}

The results of this study may only be interpreted within the context of a laboratory experiment. The first of these limitations is the participants' attention focused on listening to eight radio advertisements. This cannot be equated with the normal listening circumstances of a regular radio listener. Therefore, better levels of attention and recall can be expected here against a normal listening to some ad on the radio.

Concerning the stimuli, one of the main limitations can be derived from the use of real advertisements. Some of the script used for this research had much information, which is common in advertising. This fact can have hindered the optimal cognitive processing. Future studies using this methodology should include more appropriate texts to validate the results of the research.

Regarding the dependent variables, this study only included the self-perception of attention, as we intended to know what participants consciously thought about their attention. The goal was to assess if the results of this self-perception were different from the data obtained with a more objective variable, as it was recall. The findings showed that this self-perception, with three different measures, was very similar to the memory of the information contained in the commercials. Still, the measure of attention in this study can be considered incomplete, and future studies should address this concern, for example, by using psychophysiological techniques.

The last important limitation of this study is that the participants only listen to the commercials once. Consequently, these novel elements achieved a high impact in their attention. However, the effect attained here can be reduced with successive exposures to the same commercials, as it is habitual on radio. Although Potter et al. (2015) have not used the same audio features, these authors have demonstrated a habituation effect. Therefore, this effect should be explored in future studies.

\section{Appendix}

\section{An Example of the Advertisements}

\section{Real commercial (Version I)}

The incredible thing is that a big touch screen tablet with wifi, a camera with 4 GB of memory, and a USB port costs only 119 euros with the special conditions that Universia can offer you. Only 119 euros, because you belong to our community. Discover the personalized and interesting things your university has to offer you. For more information: conecta.universia.es. 


\section{Commercial with appeals to the listener (Version 2)}

Beginning: Hey, listen carefully: A big touch screen tablet with wifi, camera with 4 GB of memory, and a USB port can be yours for just 119 euros.

Middle: Student, only 119 euros because you belong to Universia community. Discover the personalized and interesting things your university has to offer you. End: Take note: conecta.universia.es

Commercial with music (Version 3)

Music: The incredible thing is that a big touch screen tablet with wifi, a camera with 4 GB of memory, and a USB port can be yours for just 119 euros with the special conditions that Universia can offer you.

Music: Only 119 euros because you belong to Universia community. Discover the personalized and interesting things your university has to offer you.

Music: conecta.universia.es.

\section{Commercial with sound effects (Version 4)}

Sound effect: The incredible thing is that a big touch screen tablet with wifi, a camera with 4 GB of memory, and a USB port can be yours for just 119 euros with the special conditions that Universia can offer you.

Sound effect: Only 119 euros because you belong to Universia community. Discover the personalized and interesting things your university has to offer you.

Sound effect: conecta.universia.es.

\section{Declaration of Conflicting Interests}

The author declared no potential conflicts of interest with respect to the research, authorship, and/or publication of this article.

\section{Funding}

The author received no financial support for the research, authorship, and/or publication of this article.

\section{References}

Alpert, M. I., Alpert, J. I., \& Maltz, L. N. (2005). Purchase occasion influence on the role of music in advertising. Journal of Business Research, 58, 369-376.

Baddeley, A. D., Eysenck, M. W., \& Anderson, M. C. (2015). Memory. London, England: Psychology Press.

Berti, S., \& Schröger, E. (2003). Working memory controls involuntary attention switching: Evidence from an auditory distraction paradigm. European Journal of Neuroscience, 17, 1119-1122.

Bolls, P. (2002). I can hear you, but can I see you? The use of visual cognition during exposure to high-imagery radio advertisements. Communication Research, 29, 537-563. 
Bolls, P., \& Lang, A. (2003). I saw it on the radio: The allocation of attention to high-imagery radio advertisements. Media Psychology, 5, 33-55.

Bolls, P., \& Muehling, D. (2007). The effects of dual-task processing on consumers' responses to high- and low-imagery radio advertisements. Journal of Advertising, 36(4), 35-47.

Bower, G. (1981). Mood and memory. American Psychology, 36, 129- 148.

Boyle, R., \& Coltheart, V. (1996). Effects of irrelevant sounds on phonological coding in reading comprehension and short-term memory. Quarterly Journal of Experimental Psychology, 49A, 398-416.

Brooker, G., \& Wheatley, J. J. (1994). Music and radio advertising. Advances in Consumer Research, 21, 286-290.

Chebat, J. C., Gelinas, C., \& Vaillant, D. (2001). Environmental background music and in-store selling. Journal of Business Research, 54, 115-123.

Crowder, R. G., Seranne, M. L., \& Repp, B. (1990). Physical interaction and association by contiguity in memory for the words and melodies of songs. Memory \& Cognition, 18, 469-476.

Dubé, L., Chebat, J. C., \& Morin, S. (1995). The effects of background music on consumers' desire to affiliate on buyer-seller interactions. Psychology \& Marketing, 12, 305-319.

Escera, C., Alho, K., Winkler, I., \& Naatanen, R. (1998). Neural mechanisms of involuntary attention to acoustic novelty and change. Journal of Cognitive Neuroscience, 10, 590-604.

Fraser, C., \& Bradford, A. (2013). Music to your brain: Background music changes are processed first, reducing ad message recall. Psychology \& Marketing, 30, 62-75.

Hernández, M. I. (2006). El poder de la palabra en la publicidad de radio [The power of words in advertising on radio]. Barcelona, Spain: Octaedro.

Jones, D. M. (1993). Objects, streams, and threads of auditory attention. In A. D. Baddeley \& L. Weiskrantz (Eds.), Attention, selection, awareness, and control (pp. 87-104). Oxford, UK: Oxford University Press.

Kellaris, J., Cox, A. D., \& Cox, D. (1993). The effect of background music on ad processing: A contingency explanation. Journal of Marketing, 57(4), 114-126.

Lang, A. (2000). The limited capacity model of mediated message processing. Journal of Communication, 50(1), 46-70.

Lang, A. (2006). Using the limited capacity model of motivated mediated message processing to design effective cancer communication messages. Journal of Communication, 56(S1), S57-S80.

Lang, A. (2009). The limited capacity model of motivated mediated message processing. In R. Nabi \& M. B. Oliver (Eds.), The SAGE handbook of media processes and effects (pp. 193-204). Thousand Oaks, CA: Sage.

Lynn, R. (1966). Attention, arousal, and the orientation reaction. Oxford, UK: Pergamon Press.

MacInnis, D. J., \& Park, W. C. (1991). The differential role of characteristics of music on high and low-involvement consumers' processing of ads. Journal of Consumer Research, 18, 161-173.

Martin, R. C., Wogalter, M. S., \& Forlano, J. G. (1988). Reading comprehension in the presence of unattended speech and music. Journal of Memory and Language, 27, 382-398.

Miller, D. W., \& Marks, L. J. (1992). Mental imagery and sound effects in radio commercials. Journal of Advertising, 21(4), 83-93.

Olsen, G. D. (1995). Creating the contrast: The influence of silence and background music on recall and attribute importance. Journal of Advertising, 24(4), 29-44.

Olsen, G. D. (2002). Salient stimuli in advertising: The effect of contrast interval length and type on recall. Journal of Experimental Psychology, 8(3), 168-179.

Park, C., Mark, S., \& Young, M. S. (1986). Consumer response to television commercials: The impact of involvement and background music on brand attitude formation. Journal of Marketing Research, 23, 11-24. 
Potter, R. F. (2000). The effects of voice changes on orienting and immediate cognitive overload in radio listeners. Media Psychology, 2, 147-178.

Potter, R. F. (2006). Made you listen: The effects of production effects on attention to short radio promotional announcements. Journal of Promotion Management, 12, 35-48.

Potter, R. F., \& Choi, J. (2006). The effects of auditory structural complexity on attitudes, attention, arousal, and memory. Media Psychology, 8, 395-419.

Potter, R. F., Lang, A., \& Bolls, P. D. (2008). Identifying Structural Features of Audio: Orienting responses during radio messages and their impact on recognition. Journal of Media Psychology, 20, 169-178.

Potter, R. F., Lynch, T., \& Kraus, A. (2015). I've heard that before: Habituation of the orienting response follows repeated presentation of auditory structural features in radio. Communication Monographs, 82, 359-378.

Rodero, E. (2005). Producción radiofónica [Radio production]. Madrid, Spain: Cátedra.

Rodero, E. (2011). Serial position, information density and speech rate in the recall of radio ads. Pensar la publicidad, 5(2), 255-276.

Rodero, E. (2012). See it in a radio story: Sound effects and shots to evoked imagery and attention on audio fiction. Communication Research, 39, 458-479.

Rodero, E. (2014). Serial position and attention resources to improve the recall of radio ads. Revista Latina de Comunicación Social, 68, 1-11.

Salamé, P., \& Baddeley, A. (1989). Effects of background music on phonological short-term memory. The Quarterly Journal of Experimental Psychology, 41, 107-122.

Schneider, W., Dumais, S. T., \& Shiffrin, R. M. (1984). Automatic and controlled processing and attention. In R. Parasuraman \& D. Davies (Eds.), Varieties of attention (pp. 1-17). New York, NY: Academic press.

Sharma, A. (2011). Does background music really help radio commercials? The effect of involvement on ad recall. Journal of Radio \& Audio Media, 18, 158-175.

Tabachnick, B. G., \& Fidell, L. S. (2012). Using multivariate statistics (6th ed.). Needham Heights, MA: Allyn \& Bacon.

Thorson, E., \& Lang, A. (1992). Effects on television video graphics and lecture familiarity on adult cardiac orienting responses and memory. Communication Research, 19, 346-369.

Tiitinen, H., May, P., Reinikainen, K., \& Näätänen, R. (1994). Attentive novelty detection in humans is governed by pre-attentive sensory memory. Nature, 372, 90-92.

Vincenzo, J., \& Hendrick, C. (1974). Impact of sound effects and dramatic speech on speaker perception, attitudes and speech recall. Bulletin of the Psychonomic Society, 3, 434-436.

Wallace, W. (1994). Memory for music: Effect of melody on recall of text. Journal of Experimental Psychology: Learning, Memory, and Cognition, 20, 1471-1485.

Yalch, R. F., \& Spangenberg, E. (1990). Effects of store music on shopping behavior. Journal of Services Marketing, 4(10), 31-o39.

\section{Author Biography}

Emma Rodero, $\mathrm{PhD}$ in Communication, Master in Voice Pathologies and Master in Cognition and Communication, is a Senior Lecturer in Communication and Advertising at the Pompeu Fabra University (Spain) and visiting researcher at the Institute for Communication Research (IU, US). 